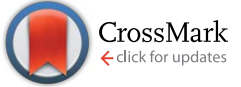

Cite this: RSC Adv., 2017, 7, 16033

Received 25th October 2016 Accepted 1st March 2017

DOI: 10.1039/c6ra25791g

rsc.li/rsc-advances

\section{Electrochemical sensor based on lead ion- imprinted polymer particles for ultra-trace determination of lead ions in different real samples $\uparrow$}

\author{
Xuan Luo, ${ }^{a}$ Weihong Huang, ${ }^{a}$ Qingye Shi, ${ }^{b}$ Wanzhen Xu, ${ }^{* a}$ Yu Luan, ${ }^{c}$ Yanfei Yang, ${ }^{c}$ \\ Huajie Wang ${ }^{\mathrm{b}}$ and Wenming Yang ${ }^{\star b}$
}

In this paper, a self-manufactured lead(॥)-selective electrode, which was based on the use of lead(॥) ion imprinted polymer particles (IIPs) to detect lead ions, was studied using differential pulse voltammetry. The synthesis and preparation of the IIPs was by precipitation polymerization with methacrylic acid (function monomer and lead-binding ligand), ethylene glycol dimethacrylate (the cross-linker) 2,2azobisisobutyronitrile (the initiator) and lead ions (the template ion) in an acetonitrile solution. The IIPS were prepared to establish the electrochemical sensor by leaching out the lead(॥) from the imprinted polymer particles, and a carbon paste electrode was modified with lead(॥) IIPS. There is a distinct difference in the response between the electrodes modified with IIPs and the electrodes modified with NIPs, which included the open circuit sorption of $\mathrm{Pb}^{2+}$ on the electrode and its reduction to its metallic form. The influence factors on the response behavior of the electrodes were investigated and optimized. The results show the introduced sensor was linear from $1.0 \times 10^{-9}$ to $7.5 \times 10^{-7} \mathrm{~mol} \mathrm{~L}^{-1}$, and the limit of detection (LOD) was $1.3 \times 10^{-11} \mathrm{~mol} \mathrm{~L}^{-1}(\mathrm{~S} / \mathrm{N}=3)$. Finally, the sensor was successfully applied to the trace determination of lead ions in various real samples.

\section{Introduction}

Heavy metal pollution refers to the environmental pollution caused by heavy metals or their compounds. With the rapid development of city expansion and industrial production, heavy metal exposure directly or indirectly into the surroundings because of non-standard discharge, such as mining, metallurgy, electroplating, chemical fertilizer production, papermaking, pesticides and other manufacturing and improper handling, batteries, and electronic waste, has increased. When heavy metals intermix in the surroundings, they will continue to occur in the environment but they do not decompose, pollute the soil, air and water, accumulate in livestock, crops and hydrobios and enter the human body through food chain enrichment. Lead(II), a heavy metal, leads to plumbism for the vital organs of animals and humans, such as anemia, hepatopathy, serious brain damage, kidney malfunctioning, hematological damage, etc. ${ }^{1}$ Thus, lead contamination has become a focus. Therefore,

${ }^{a}$ School of the Environment and Safety Engineering, Jiangsu University, Zhenjiang 212013, China.E-mail: xwz09@ujs.edu.cn

${ }^{b}$ School of Materials Science and Engineering, Jiangsu University, Zhenjiang 212013, China. E-mail: ywm@ujs.edu.cn

${ }^{c}$ Zhenjiang Institute for Drug Control of Jiangsu Province, Zhenjiang 212013, China

† Electronic supplementary information (ESI) available. See DOI: 10.1039/c6ra25791g a detection method should be found to test lead(II) in order to prevent the damage from poisoning.

For this purpose, several methods have been proposed, especially by means of a wide range of spectrometric methods, such as electrothermal atomization atomic absorption spectrometry (ET-AAS), ${ }^{2,3}$ sequential multi-element flame atomic absorption spectrometry, ${ }^{4}$ graphite furnace atomic absorption spectrometry (GFAAS), ${ }^{5}$ electrothermal atomic absorption spectrometry, ${ }^{6}$ inductively coupled plasma-mass spectrometry (ICPMS), ${ }^{7}$ hydride generation atomic absorption spectrometry ${ }^{8}$ and flame atomic absorption spectrometry (FAAS). ${ }^{9}$ These methods have the advantages of high sensitivity, selectivity and accuracy, but still have weakness, such as the expensive cost, professional operating and time consumption. Thus, different kinds of sensors, including optical, ${ }^{\mathbf{1 0}}$ potentiometric ${ }^{\mathbf{1 1}}$ and voltammetric ${ }^{12,13}$ sensors, have been widely used for lead determination. These highly adopted techniques for the determination of metal ions have the advantages of high sensitivity, low cost, easy operation and etc. In order to enhance the sensitivity and selectivity of the electrochemical determination of lead(II), chemically modified materials on the electrode have been attractive to researchers in the past decades. The modifiers used include bismuth, ${ }^{\mathbf{1 4 1 5}}$ organic chelating groups, ${ }^{\mathbf{1 6 , 1 7}}$ PAN-incorporated Nafion, ${ }^{18}$ zeolite, ${ }^{19} \mathrm{SiO}_{2}-\mathrm{Al}_{2} \mathrm{O}_{3}$ mixed-oxide, ${ }^{20}$ clay nano particles $^{21}$ and silica. ${ }^{22}$ Moreover, a suitable selectivity is not provided 
by these materials toward lead(II) in some situations with interfering ions like $\mathrm{Cu}(\mathrm{II}), \mathrm{Ag}(\mathrm{I})$, etc. Therefore, there is still a pressing need to propose a high selective modifier for testing lead(II). Molecular imprinting technology is a potential method for lead(II) detection.

Molecular imprinting technology has unique advantages such as superior specificity and predetermined selectivity. Molecularly imprinted polymers (MIPs) demonstrate good chemical and thermal stability against environmental interference. $^{23}$ To extract target molecules from complex samples accurately, this method has become one of the most widely used techniques in the field of separation and enrichment materials in recent years.

Ion-imprinted polymers (IIPs) are similar to MIPs with different recognition for target ions after preparing IIPs, which preserve the virtues of MIPs. The prepared polymers show selective binding of a specific cation and can be equipped with complexing agents through the coordination bond to form stable intermolecular forces matching the charge, coordination geometry and size of the target cation. ${ }^{24}$

In this paper, a self-manufactured carbon paste electrode sensor was prepared for the detection of lead ions, and they use an ion-imprinted polymer technique combined with an electrochemical detection method. Ion-imprinted polymer techniques have high selectivity, and electrochemistry detection methods have excellent sensitivity. This new ion-imprinted polymer modified carbon paste sensor is high selective for lead ions, easy to operate and provides cheap, sensitive detection of low levels of lead ions in aqueous solution.

\section{Experimental}

\subsection{Materials}

Paraffin oil, activated charcoal, pure graphite powder, methanol (Augmented Reality), $\mathrm{PbCO}_{3}$, acetic acid (HOAc), anhydrous sodium acetate, hydrogen peroxide $\left(\mathrm{H}_{2} \mathrm{O}_{2}\right)$ and thiourea were purchased from Sinopharm Chemical Reagent Co., Ltd (Shanghai, China). The acetate buffer solutions $\left(0.2 \mathrm{~mol} \mathrm{~L}^{-1}\right)$ were prepared with $\mathrm{CH}_{3} \mathrm{COONa}$ and $\mathrm{CH}_{3} \mathrm{COOH}$. Methacrylic acid, ethylene glycol dimethacrylate (EGDMA) and 2,2-azobisisobutyronitrile (AIBN) were obtained from Aladdin Chemistry (Shanghai, China). Acetonitrile was purchased from Lingfeng Chemical Reagent Co., Ltd (Shanghai, China). Hydrochloric acid ( $\mathrm{HCl}$ ) was from Yongfeng Chemical Reagent Co., Ltd. (Jiangsu, China). Nitric acid $\left(\mathrm{HNO}_{3}\right)$ was purchased from Yangzhou Hubao Chemical reagents Co., Ltd. (Yangzhou, China).

\subsection{Instrument}

All the electrochemical measurements were obtained with a three-electrode system using a CHI760E electrochemical workstation (Chenhua, Shanghai, China) with a conventional three electrode configuration. A self-manufactured lead(II) ionimprinted polymer modified carbon paste electrode (IIP-CPE) was employed as the working electrode with a potassium chloride $(\mathrm{KCl})$ saturated calomel electrode (SCE) and a Pt wire electrode as the reference and auxiliary electrodes, respectively. A personal computer was used to save all the electrochemical data and perform the processing. Fourier Transform Infrared (FT-IR) spectra $\left(4000-400 \mathrm{~cm}^{-1}\right)$ in $\mathrm{KBr}$ were recorded using a Nicolet NEXUS-470FT-IR spectrometer (USA). The data of the single point surface area at $P / P_{\mathrm{o}}$ was obtained with Micromeritics TriStar II3020 (America). The real sample pretreatment was used with a MSP-6600 microwave digestion system (Rayleigh, China). The $\mathrm{pH}$ measurement was performed with a Sartorius model PB-21 pH/mV meter (Germany). Scanning electron microscopy (SEM) was performed using a Zeiss Merlin Compact instrument (Germany).

\subsection{Synthesis of lead(II) ion imprinted polymer (IIP) and non- imprinted polymer particles (NIP)}

In order to prepare the $\mathrm{Pb}$ (II) imprinted polymer, $18 \mathrm{mmol}$ of methacrylic acid and $6 \mathrm{mmol}$ of $\mathrm{PbCO}_{3}$ were added to $25 \mathrm{~mL}$ acetonitrile and stirred for $24 \mathrm{~h}$ at room temperature in a 100 $\mathrm{mL}$ glass flask. The mixture was then centrifuged and the supernatant liquid was separated for the synthesis of the polymer. EGDMA (25 mmol) was used as the cross-linker and $0.03 \mathrm{~g}$ AIBN the initiator, and they were dissolved in $8 \mathrm{~mL}$ acetonitrile and added to the supernatant solution. At the same time, dissolved oxygen in the resulting mixture was removed by purging with high purity nitrogen for $20 \mathrm{~min}$. The polymerization was carried out in an oil bath at $65{ }^{\circ} \mathrm{C}$ for $24 \mathrm{~h}$. The prepared polymer particles were washed with ethanol to remove the unreacted materials. Then, a $1 \mathrm{M} \mathrm{HCl}$ solution and $0.1 \mathrm{M}$ thiourea solution were used to remove the target ions from the polymer particles. Finally, the prepared particles were washed with plenty of distilled water and dried under vacuum at $60{ }^{\circ} \mathrm{C}$ in a desiccator until a powder formed (Fig. 1). The non-imprinted polymer was also synthesized in the same way without the template lead ions.

\subsection{Preparation of IIP-CPE}

The ion-imprinted polymer modified carbon paste electrode (IIP-CPE) was prepared according to the optimized conditions. A mixture of leached IIP $(20 \% \mathrm{w} / \mathrm{w})$, graphite powder and paraffin oil ( $50: 30 \% \mathrm{w} / \mathrm{w})$ were milled in a mortar with a pestle to construct the mixed paste of the leached IIP-CPE. The prepared paste was used to fill a hole (3 $\mathrm{mm}$ in diameter) at the end of a carbon paste working electrode and compacted. Then, the working electrode was polished on the weighing paper to make sure the surface was smooth. To extrude a thin layer of the electrode surface, the electrode can be reused after each experiment by renewing the electrode surface on the weighing paper (Fig. 1).

\subsection{Real sample pretreatment}

The microwave digestion system used for digesting flour and rice samples. These two samples were weighed, ground to powder using a mortar and pestle and sieving, then weighed again before digestion. In this paper, powdered flour and rice samples ( $0.5 \mathrm{~g}$ of flour powder, $0.5 \mathrm{~g}$ of rice powder) were precisely added into two microwave digestion tanks followed by 


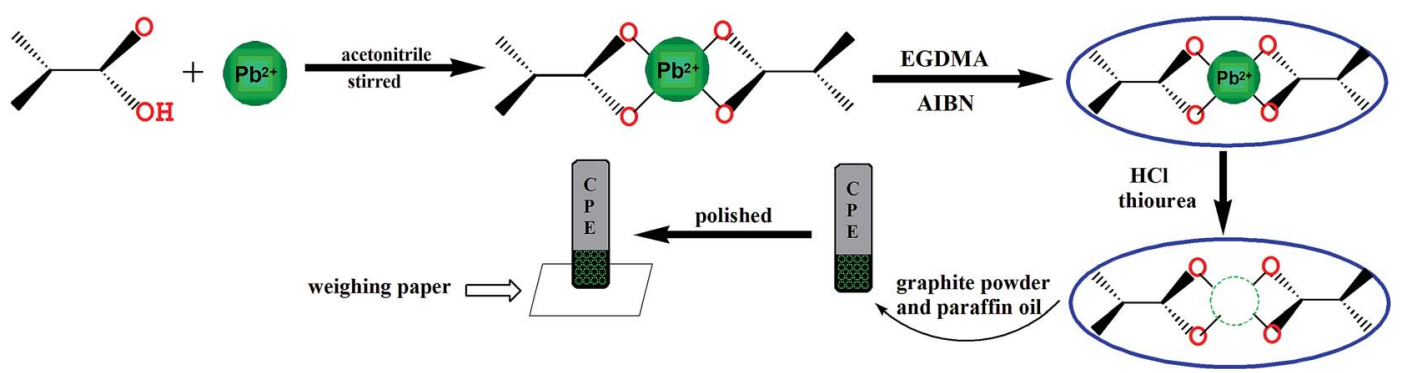

Fig. 1 The fabrication process for the preparation of lead-imprinted polymer particles and IIP-CPE.

the addition of $10 \mathrm{~mL}$ concentrated $\mathrm{HNO}_{3}$ and $1 \mathrm{~mL}$ concentrated $\mathrm{H}_{2} \mathrm{O}_{2}$. After $2 \mathrm{~h}$ of reaction at ambient temperature, the mixtures were digested in the microwave digestion system. After digesting, the mixtures were heated and gently boiled until about $2 \mathrm{~mL}$ of digestion solution were left. Subsequently, $5 \mathrm{~mL}$ of deionized water were added, and the resulting solution was boiled again to $1 \mathrm{~mL}$. After cooling, the solutions were diluted to $50 \mathrm{~mL}$ with acetate buffer, and the $\mathrm{pH}$ was adjusted to 5 for the detection. For the detection of the water sample, the polyethylene bottles filled with samples were washed with detergent, water, diluted nitric acid and water in sequence. The samples $(50 \mathrm{~mL})$, which were taken from Yudai River (Jiangsu University) and tap water, were filtered through a cellulose filter membrane (pore size $0.22 \mu \mathrm{m}$ ) immediately. Then, the water samples were adjusted to a $\mathrm{pH}$ of 5.0 with acetate buffer according to optimized experimental conditions.

\subsection{Determination procedure}

Electrochemical measurements were performed by differential pulse voltammetry (DPV). A 3-step procedure was followed for the voltammetric detection of lead(II) using the prepared electrodes. The electrodes were firstly incubated in $\mathrm{Pb}^{2+}$ solutions at pH 5.0 for $80 \mathrm{~s}$. Then, they were rinsed and placed in the electrochemical cell containing $10 \mathrm{~mL}$ of $0.12 \mathrm{M} \mathrm{HCl}$. Before the DPV scan, a negative pre-potential of $-1.0 \mathrm{~V}$ was applied to the electrode for $40 \mathrm{~s}$ to reduce the recognized target ions. Finally, the differential pulse voltammetry scan was conducted from $-0.8 \mathrm{~V}$ to $0.0 \mathrm{~V}$.

\section{Results and discussion}

\subsection{Characterization of IIP}

Scanning electron microscopy (SEM), Fourier Transformed Infrared Spectroscopy (FTIR) and surface area were used to represent the prepared nanosized imprinted polymer.

The morphology of the lead-IIP was evaluated by scanning electron microscopy and is shown in Fig. 2(a). Fig. 2(a) showed the lead-IIP is $1 \mu \mathrm{m}$ and $100 \mathrm{~nm}$. Different polymeric particle sizes ranged from $60 \mathrm{~nm}$ to $280 \mathrm{~nm}$. As a consequence, the leadIIP can be used as the selective solid phase for the detection of trace lead ions.

In all recorded regions, except the region of $\sim 1500-1700$ $\mathrm{cm}^{-1}$, there was no considerable difference among the FT-IR spectra of the unleached IIP, leached IIP and NIP. The FT-IR spectra are shown in Fig. 2(b)-(d), respectively. In Fig. 2(b), the peak at $1730.21 \mathrm{~cm}^{-1}$ is ascribed to the $\nu_{\mathrm{C}=\mathrm{O}}$ of the carboxylic acid group of methacrylic acid, and the strong stretching vibration bands at $1727.21 \mathrm{~cm}^{-1}$ and $1730.86 \mathrm{~cm}^{-1}$ in Fig. 3(c) and (d) were situated mainly at the surface of the polymeric particles. An evident band for the unleached IIP can be observed at $1639.45 \mathrm{~cm}^{-1}$, ascribed to the $-\mathrm{C}=\mathrm{O}$, and linked to $\mathrm{Pb}^{2+}$ coordination bonding. This peak is less strong than that located at $1730.21 \mathrm{~cm}^{-1}$ because these types of $-\mathrm{C}=\mathrm{O}$ groups are mainly situated in the interior sections of the IIP particles. After washing the unleached IIP, by reason of the removal of the $\mathrm{Pb}^{2+}$ ions to a considerable decrease at the height of the vibration band of the $-\mathrm{C}=\mathrm{O}$ coordinated to $\mathrm{Pb}^{2+}$. The above analysis can be evidence for the existence and proper interaction of the selective recognition sites in the IIP particles, which are created during the imprinting process.

As evidence by the $\mathrm{N}_{2}$ sorption test, the imprinted polymer particles showed a specific surface area of $134.89 \mathrm{~m}^{2} \mathrm{~g}^{-1}$, whereas the non-imprinted polymer particles only had a specific surface area of $79.42 \mathrm{~m}^{2} \mathrm{~g}^{-1}$. These indicated that the surface area of the imprinted polymer particles was larger than the non-imprinted particles. More binding sites for the template ions formed on the surface of the imprinted particles.

\subsection{Optimisation of lead(II) extraction conditions on the electrode response}

3.2.1 Effect of IIP-CPE composition. The composition of the self-manufactured IIP-CPEs were formed by graphite power, paraffin oil and ion imprinted polymers in different percentages. The optimum composition of IIP was studied. In a series of experiments, the composition percentage of the liquid and solid phase was $3: 7$. That means the amount of paraffin oil was at $30 \%$, and in the $70 \%$ of the solid phase, the amount of IIP/ graphite changed. Under the same experimental conditions for the extraction and determination procedures, the voltammetric signals were tested at a concentration of $5.0 \times 10^{-7} \mathrm{~mol}$ $\mathrm{L}^{-1}$ lead. For good conductivity, carbon black, activated charcoal and graphite powder were chosen to mix with paraffin oil at the confirmed composition percentage, and tested using cyclic voltammetry in an acetic acid buffer solution $(\mathrm{pH}=5)$ without added ion-imprinted polymers. As shown in Fig. S1, $\dagger$ the graphite powder mixed with paraffin had the best current response. Carbon black, activated charcoal and graphite powder are allotropes of carbon with different structures, and when 
(a)

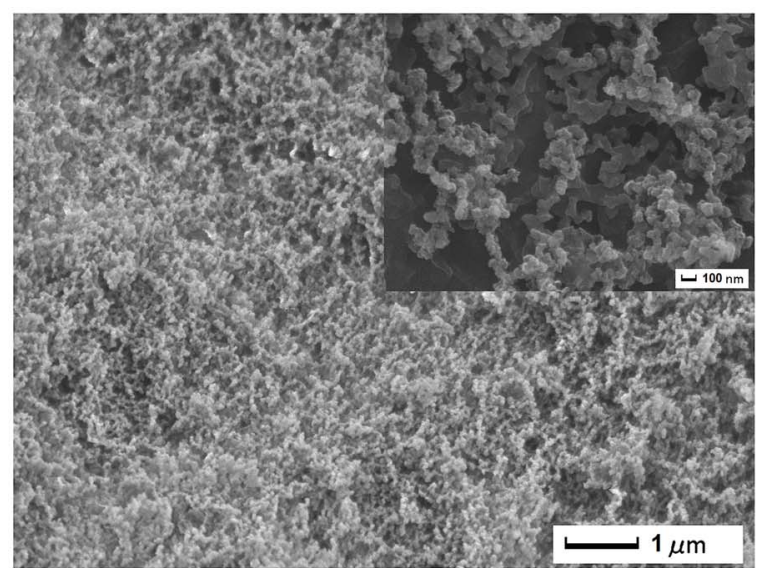

(c)

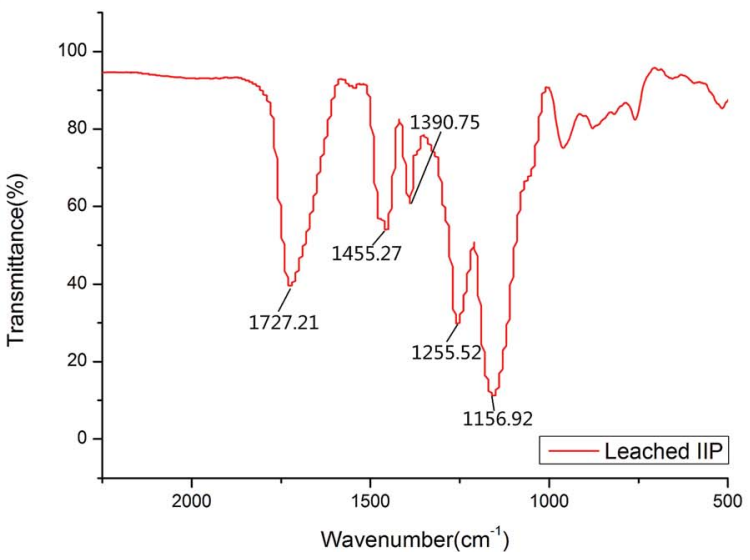

(b)

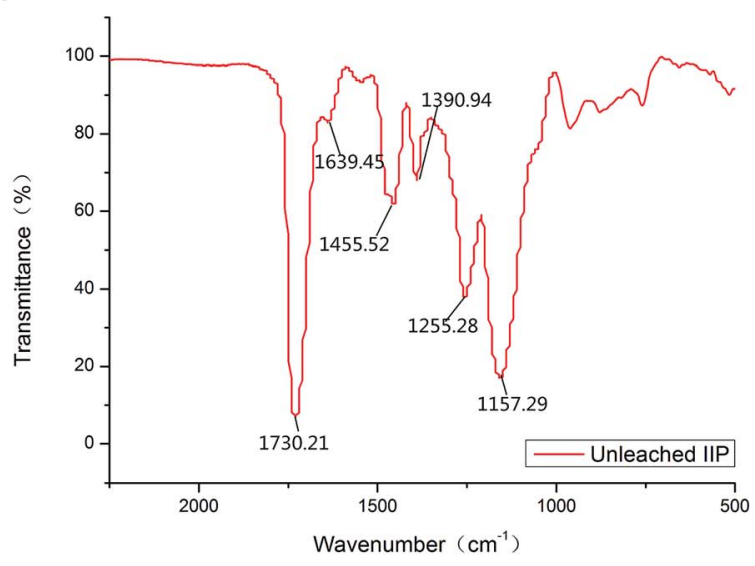

(d)

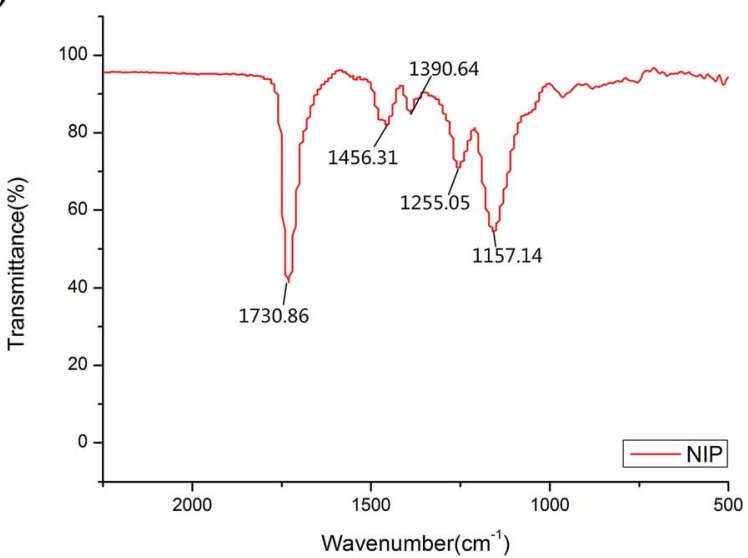

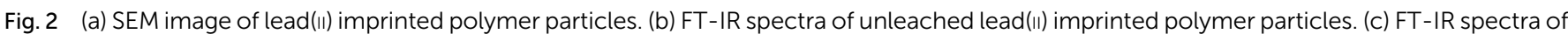
leached lead(॥) imprinted polymer particles. (d) FT-IR spectra of non-imprinted polymer particles.

they mixed with paraffion oil in the same proportion, the influence of the different spatial structures leads to various conductivities. The IIP-CPE with graphite powder mixed with paraffin was chosen for the following studies.

Not only the experimental materials influence the current, but also the amount of IIP in the modified CPE played a key role in the response characteristics of the IIP-CPEs. As shown in Fig. S2, $\uparrow$ the voltammetric signal was increased with the increasing IIP content, and the chosen composition was $5 \%$, $10 \%, 15 \%, 20 \%$ and $25 \%$. Up to $20 \%$, with the increasing percentage of the IIP, the IIP-CPE voltammetric signal decreased considerably because of the conductivity of the electrode. Therefore, the selected percentage for a graphite powder/IIP/paraffin oil electrode was $50 \% / 20 \% / 30 \%$ as the optimal condition for the preparation of IIP-CPE in following studies.

3.2.2 The $\mathbf{p H}$ impact. The reaction of extracting $\mathrm{Pb}^{2+}$ was in the acetic acid buffer solution, and the solution had different pHs for various experiments. For the optimal $\mathrm{pH}$ in this procedure, the $\mathrm{pH}$ of the buffer solution was studied. In order to test the influence of the $\mathrm{pH}$, the prepared electrode was inserted into a diverse $\mathrm{pH}$ value buffer solution including $5.0 \times 10^{-7} \mathrm{~mol}$ $\mathrm{L}^{-1}$ lead ions for $80 \mathrm{~s}$. Finally, the electrode was removed from the solution and immersed into the solution of the electrochemical cell. Fig. $\mathrm{S} 3 \uparrow$ shows the results of this experiment. The $\mathrm{pH}$ for the method in this work is a crucial parameter for lead(II) extraction. The optimal $\mathrm{pH}$ was found to be 5.0 for the proposed method. When the $\mathrm{pH}$ value is lower than 5.0, the electrode signals showed a decreasing tendency because of the decrease in the actual amount of the target ion extracted into the electrode. This is probably due to the protonation of oxygen moieties of the selective sites of the IIP, the high concentration of $\mathrm{H}^{+}$ ions competed with the $\mathrm{Pb}^{2+}$ ions and weaken the interactive force of the $\mathrm{Pb}^{2+}$ with the oxygen moieties, which consist of the selective sites of IIP. At the $\mathrm{pH}$ of 5.0, the electrode signal was optimum. At higher $\mathrm{pH}$ values, a considerable decrease in the electrode signal is displayed probably because the $\mathrm{Pb}^{2+}$ ions react with $\mathrm{OH}^{-}$ions to form hydroxide sediments. ${ }^{25}$

3.2.3 Optimization of the pre-potential time. For recording the stable oxidation peak, a definite pre-potential time should be confirmed because of the influence of the pre-potential magnitude on the sensor. Thus, the effect of the pre-potential time on the response magnitude of the manufactured sensor was tested. The time of the applied pre-potential $(-1.0 \mathrm{~V})$ was increased from $10 \mathrm{~s}$ to $70 \mathrm{~s}$ to investigate the influence on the sensor performance. In the range of 10-40 s, the magnitude 


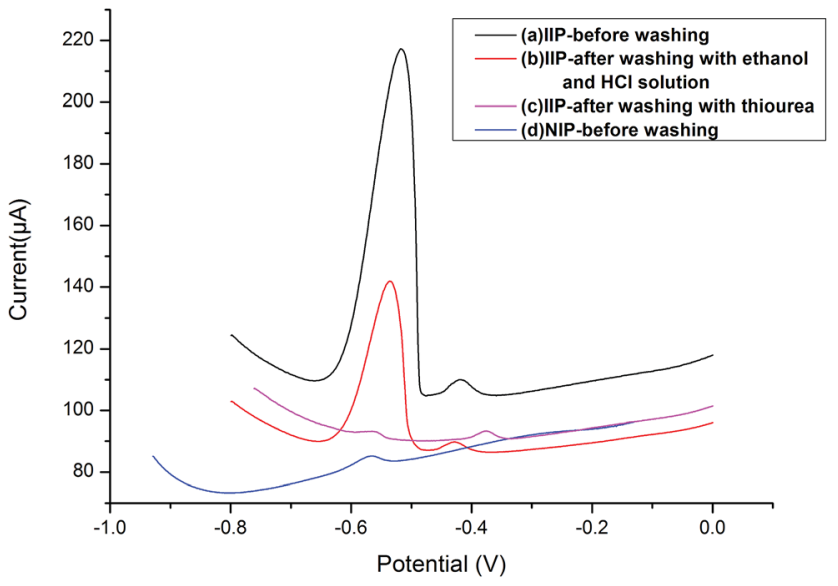

Fig. 3 Comparison of differential pulse voltammetry responses of the IIP-CP electrode and NIP-CP electrode with and without the washing step; $\left[\mathrm{Pb}^{2+}\right]=5.0 \times 10^{-7} \mathrm{~mol} \mathrm{~L}-1$, extraction time $80 \mathrm{~s}$, stripping voltammetry conditions: $\mathrm{E}$-conditioning $=-1.0 \mathrm{~V}$, conditioning time $=$ $40 \mathrm{~s}$, scan rate $=0.1 \mathrm{~V} \mathrm{~s}^{-1}$.

signal of the electrodes obviously increased. Higher than $40 \mathrm{~s}$, maybe because of the diffusion of species far from the electrode surface, the response slightly decreased (Fig. S4†). Thus, a prepotential time of $40 \mathrm{~s}$ was chosen for further study.

(a)

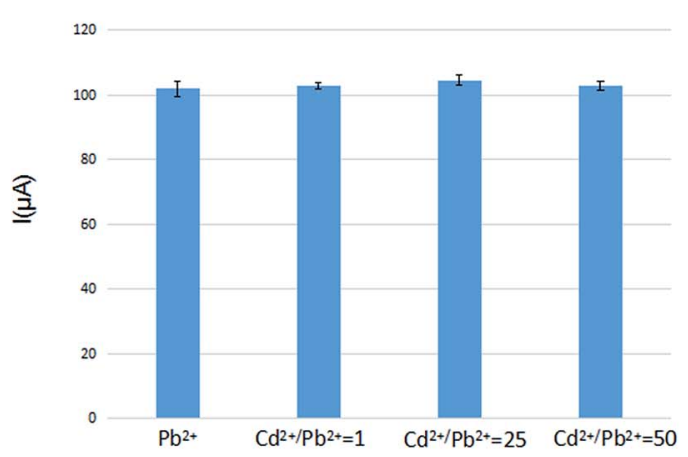

(c)

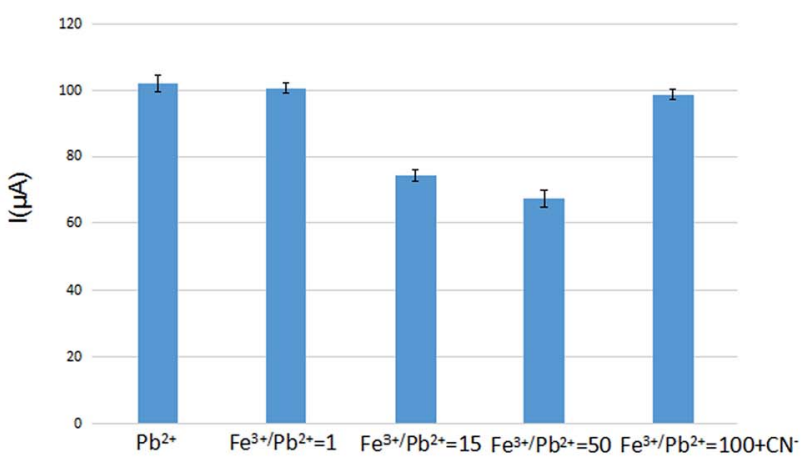

3.2.4 Extraction time conditions. The influence of extraction time was researched from 20 to $120 \mathrm{~s}$ for the sensitivity of the prepared lead(II) sensor, while keeping the other experiment parameters unchanged. Fig. $\mathrm{S} 5 \dagger$ illustrates the electrochemical signal of different extraction times. The curve in Fig. S5† shows an increasing trend in the electrochemical signal by increasing the extraction time in the extracted amount of $\mathrm{Pb}^{2+}$ ions, and the current intensity was the highest until an incubation time of about $60 \mathrm{~s}$. With a further increase in the incubation time of the $\mathrm{Pb}^{2+}$ ions, the intensity of the voltammetric signal remained constant. In order to stabilize the analyzing time, a time of $80 \mathrm{~s}$ was selected for further studies.

\subsection{Comparison of the IIP-CP electrode with the NIP-CP electrode for absorption properties}

The carbon paste electrode modified with IIP or NIP was incubated in the $\mathrm{Pb}^{2+}$ solution $\left(5.0 \times 10^{-7} \mathrm{~mol} \mathrm{~L}^{-1}\right)$. Then, the electrode was inserted into the electrochemical cell, and a negative potential of $-1.0 \mathrm{~V}$ was applied to the electrode followed by a different pulse voltammetry technique for the test of lead ions. As shown in Fig. 3, the obtained signal for IIP-CPE before washing (voltammogram, a) is noticeably higher than that of NIP-CPE (voltammogram, d), indicating the selective functional cavities in the IIP-CPE were formed, and the (b)

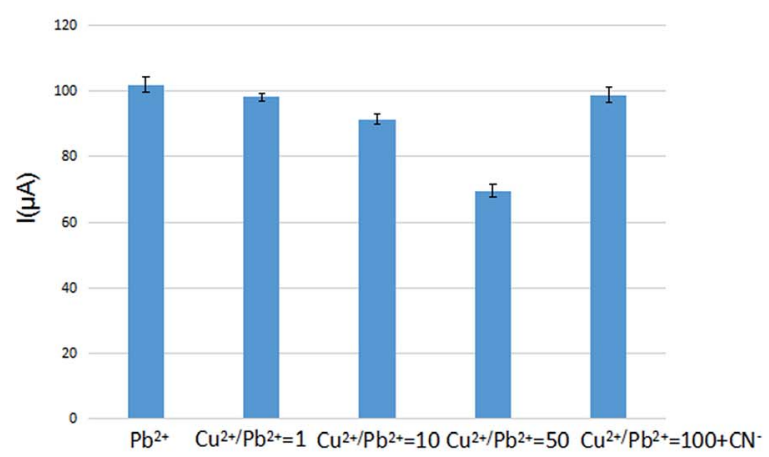

(d)

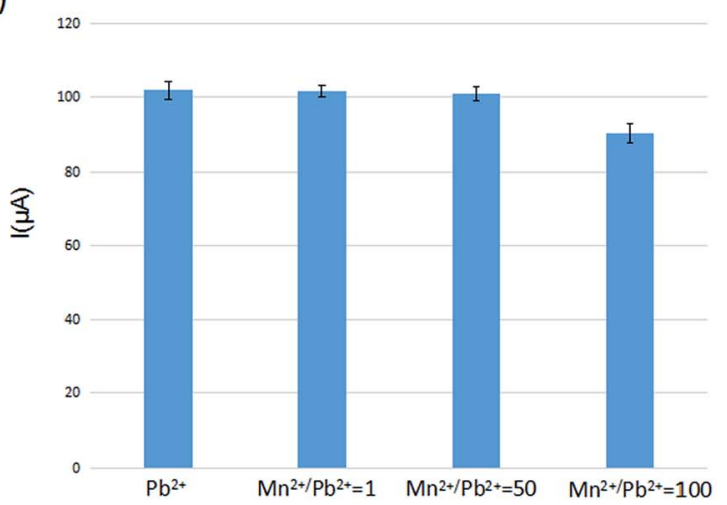

Fig. 4 Comparison of the electrode selectivity of $\mathrm{Pb}^{2+}$ ion in the presence of difference interfere ions $\left((\mathrm{a}) \mathrm{Cd}^{2+}(\mathrm{b}) \mathrm{Cu}^{2+}(\mathrm{c}) \mathrm{Fe}^{3+}(\mathrm{d}) \mathrm{Mn}^{2+}\right)$ at various concentrations: $\left[\mathrm{Pb}^{2+}\right]=5.0 \times 10^{-7} \mathrm{~mol} \mathrm{~L}{ }^{-1}$, extraction time $80 \mathrm{~s}$, stripping voltammetry conditions: E-conditioning $=-1.0 \mathrm{~V}$, conditioning time $=40 \mathrm{~s}$, scan rate $=0.1 \mathrm{~V} \mathrm{~s}^{-1}(n=5)$. 
selectivity of IIP-CPE is superior to NIP-CPE because of the functional cavities. After washing the electrode modified with IIP to remove the lead ions (voltammogram a, b and c), the electrode signals decreased in voltammograms $\mathrm{a}, \mathrm{b}$ and $\mathrm{c}$, which means the selective functional cavities in the IIP were created in the polymerization procedure. When the IIP was washed with ethanol, $\mathrm{HCl}$ solution and thiourea solutions, unreacted substances and weak cohesion were washed from the surface sites of IIP.

\subsection{Selectivity of IIP-CPE}

The selectivity of IIP in the IIP-CPE was investigated by incubation in different solutions, including a mixture of $\mathrm{Pb}^{2+}(5.0 \times$ $10^{-7} \mathrm{~mol} \mathrm{~L}^{-1}$ ) and some potential interfering cations at various concentrations, and subsequently analyzed by different pulse voltammetry. Sample $\mathrm{Pb}^{2+}$ voltammograms obtained are in the first column of Fig. 4(a)-(d) and S6, $\uparrow$ as a comparison with other columns of different cations at various concentrations. It can be seen that the presence of $\mathrm{Cd}^{2+}, \mathrm{Co}^{2+}, \mathrm{Cu}^{2+}$ and $\mathrm{Fe}^{3+}$ in the $\mathrm{Pb}^{2+}$ solution, at identical concentrations, possessed negligible effects on the voltammetric signal of lead ions. In Fig. 4(a) and $\mathrm{S} 6, \uparrow$ the presence of $\mathrm{Cd}^{2+}$ at a $\mathrm{Cd}^{2+} / \mathrm{Pb}^{2+}$ ratio of 50 and $\mathrm{Co}^{2+}$ at a $\mathrm{Co}^{2+} / \mathrm{Pb}^{2+}$ ratio of 100 did not affect significantly the $\mathrm{Pb}^{2+}$ signal. However, in Fig. 4(b) the presence of $\mathrm{Cu}^{2+}$ at a $\mathrm{Cu}^{2+} / \mathrm{Pb}^{2+}$ ratio of 10 possessed an effect on the $\mathrm{Pb}^{2+}$ signal. By increasing the $\mathrm{Cu}^{2+} / \mathrm{Pb}^{2+}$ ratio to 50 , the voltammetric signal of $\mathrm{Pb}^{2+}$ further decreased, indicating that for occupying the selective sites in the IIP, these two different kinds of ions have a competitive relationship. The same behavior can be seen in the case of $\mathrm{Fe}^{3+}$ in Fig. 4(c). The addition of $\mathrm{CN}^{-}$bonded with $\mathrm{Cu}^{2+}$ decreases the influence on the detection of $\mathrm{Pb}^{2+}$ using the selfmanufactured electrode. In Fig. 4(d), the presence of $\mathrm{Mn}^{2+}$ at a $\mathrm{Mn}^{2+} / \mathrm{Pb}^{2+}$ ratio of 75 cannot influence the current signal of $\mathrm{Pb}^{2+}$, but with increasing the $\mathrm{Mn}^{2+} / \mathrm{Pb}^{2+}$ ratio to 100 the signal of $\mathrm{Pb}^{2+}$ slightly decreased. These observations indicate that a sophisticated arrangement of carboxylic acid groups in the pre-designed cavity of an IIP led to an interesting selectivity for the target ion. The interference levels of several ions, including $\mathrm{Cd}^{2+}, \mathrm{Co}^{2+}, \mathrm{Zn}^{2+}, \mathrm{Cr}^{3+}, \mathrm{Hg}^{2+}, \mathrm{Ag}^{+}, \mathrm{Mn}^{2+}, \mathrm{Cu}^{2+}, \mathrm{Fe}^{3+}$ and alkali, which are usually present with lead ions in complex matrices, are summarized in Table S1. $\dagger$ The tolerance limit was established as the maximum concentration of foreign species that caused a relative error of $5 \%$ in the analytical signal. This table shows that the presence of alkaline cations as well as other interfering cations such as $\mathrm{Cd}^{2+}, \mathrm{Co}^{2+}, \mathrm{Zn}^{2+}, \mathrm{Hg}^{2+}, \mathrm{Cr}^{3+}, \mathrm{Ag}^{+}$do not significantly influence the electrode signal. A 100-fold excess of $\mathrm{Mn}^{2+}, 15$-fold excess of $\mathrm{Fe}^{3+}$ and 10-fold excess of $\mathrm{Cu}^{2+}$ influence the detection of $\mathrm{Pb}^{2+}$ significantly. By adding $\mathrm{CN}^{-}$ (0.005 mol L ${ }^{-1}$ ) in the $\mathrm{Pb}^{2+}$ solution, the $\mathrm{Pb}^{2+}$ signal of the prepared sensor reached a 25-fold and 100-fold excess for $\mathrm{Fe}^{3+}$ and $\mathrm{Cu}^{2+}$, decreasing the interference effect of $\mathrm{Cu}^{2+}$ and $\mathrm{Fe}^{3+}$. The interference of $\mathrm{Mn}^{2+}$ slightly influenced $\mathrm{Pb}^{2+}$.

\subsection{Analytical characterization of IIP-CPE}

In order to evaluate the reproducibility of the IIP-CP electrode, $5.0 \times 10^{-7} \mathrm{~mol} \mathrm{~L}^{-1} \mathrm{~Pb}^{2+}$ solution was determined by five separately produced electrodes. Experimental results

Table 1 Determination of $\mathrm{Pb}^{2+}$ in several real samples by the proposed method

\begin{tabular}{lccll}
\hline Sample & $\begin{array}{l}\text { Added } \\
(\mathrm{nM})\end{array}$ & $\begin{array}{l}\text { Found } \\
(\mathrm{nM})\end{array}$ & $\begin{array}{l}\text { RSD } \\
(n=3)(\%)\end{array}$ & $\begin{array}{l}\text { Recovery } \\
(\%)\end{array}$ \\
\hline Flour & - & $0.012^{a}$ & 7.5 & - \\
\multirow{2}{*}{ Rice } & $0.1^{a}$ & $0.111^{a}$ & 8.6 & 99.1 \\
Tap water & - & $0.064^{a}$ & 7.7 & - \\
& $0.1^{a}$ & $0.17^{a}$ & 2.2 & 103.7 \\
Yudai river water & - & 18.1 & 5.7 & - \\
& 50 & 67.7 & 2.5 & 99.4 \\
& 50 & 97.2 & 3.7 & - \\
& & 150.4 & 2.5 & 102.1
\end{tabular}

${ }^{a}$ The concentration unit for flour and rice is $\mu \mathrm{g} \mathrm{g}^{-1}$.

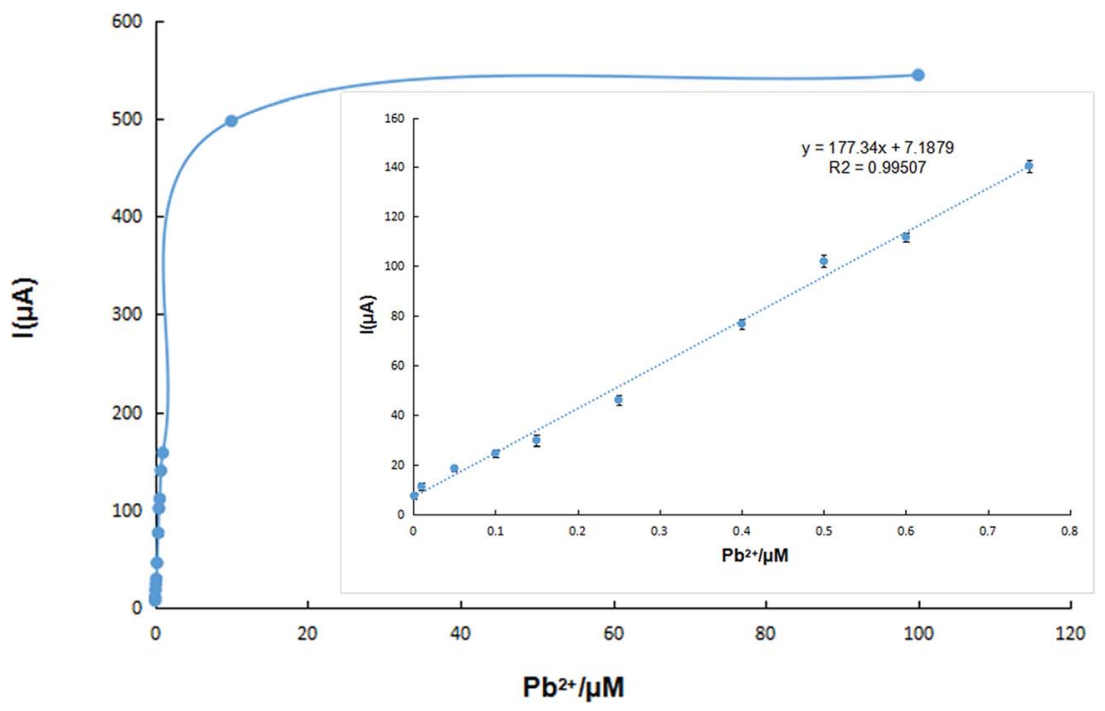

Fig. 5 Calibration curve of the lead(॥) ion sensor in the optimized conditions; inset: the linear range of the calibration curve $(n=5)$. 
Table 2 Comparison of the IIP-CP electrode with some previously reported $\mathrm{Pb}^{2+}$ voltammetric sensors

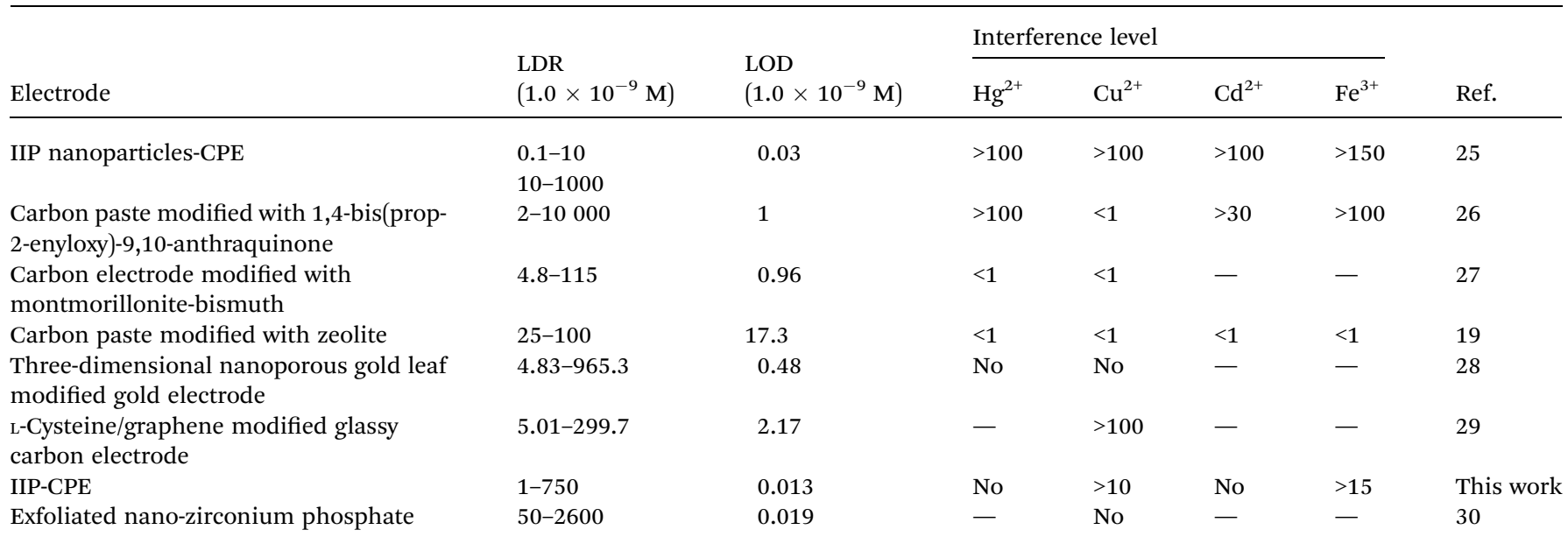

were used to calculate an RSD $\%$ equal to $2 \%$ for the described determination. Moreover, five separate determinations of $\mathrm{Pb}^{2+}$ by the same electrode resulted in an RSD $\%=4.76 \%(n=$ $5)$. Thus, the repeatability of the method can be referenced. After refreshing the electrode surface by polishing the electrode surface on weighing paper, the linear range of the prepared sensor was detected in the $\mathrm{Pb}^{2+}$ solution of different concentrations. In Fig. 5, the calibration graph of the produced sensor showed a linear relationship over the $\mathrm{Pb}^{2+}$ concentration in the range of $1.0 \times 10^{-9}$ to $7.5 \times$ $10^{-7} \mathrm{~mol} \mathrm{~L}^{-1}$ with a detection limit of $1.3 \times 10^{-11} \mathrm{~mol} \mathrm{~L}^{-1}$ $(\mathrm{S} / \mathrm{N}=3)$.

\subsection{Real sample detection}

To evaluate the feasibility of the developed electrochemical sensor for routine analysis, the IIP-CP electrode was applied to detect lead(II) in four kinds of samples, which are flour, rice, tap water and Yudai River water. Thus, $50 \mathrm{~mL}$ of those samples were spiked with different concentrations of lead(II). Then, the determination method was executed step by step, according to the proposed procedure. The results of the above studies are summarized in Table 1 and clearly certify the applicability of this method for determination of $\mathrm{Pb}^{2+}$ in various real samples.

\subsection{Comparison of the figures of the prepared sensor with those of the previous method}

In Table 2, the manufactured IIP-CP sensor is compared with other previous voltammetric sensors with a number of analytical characteristics including the linear dynamic range (LDR), limit of detection (LOD) and interference levels of $\mathrm{Hg}^{2+}, \mathrm{Cd}^{2+}$, $\mathrm{Cu}^{2+}$ and $\mathrm{Fe}^{3+}$ in the literature. As can be seen, the IIP-CP electrode shows very good analytical characteristics compared to the majority of the depicted sensors. The IIP-CP electrode has the lowest limit of detection among the list voltammetric sensors. ${ }^{19,25-30}$

\section{Conclusion}

In this paper, the self-manufactured carbon paste electrode sensor based on the IIP was made for the determination of lead ions. The imprinted electrochemical sensor was linear from 1.0 $\times 10^{-9}$ to $7.5 \times 10^{-7} \mathrm{~mol} \mathrm{~L}^{-1}$, and the limit of detection (LOD) was $1.3 \times 10^{-11} \mathrm{~mol} \mathrm{~L}^{-1}(\mathrm{~S} / \mathrm{N}=3)$. The results show the outstanding selectivity and sensitivity for the electrochemical determination of lead ions, and it resists the common potential interfering agents for good application in real water and food samples. The selective electrochemical sensor will be widely used because of its ease of preparation and low-cost.

\section{Acknowledgements}

This work was sponsored by the National Natural Science Foundation of China (No. 21677064), Jiangsu Natural Science Foundation of China (No. BK20151323, BK20151337), Postdoctoral Science Foundation of China (No. 2015T80515), the Scientific Research Foundation of Jiangsu University (No. Y14A105, Y14A125).

\section{References}

1 M. Behbahani, H. S. Abandansari, M. Salarian, M. Babapour, A. Bagheri and M. R. Nabid, Microchim. Acta, 2013, 181, 129137.

2 M. A. Belarra, C. Crespo, M. Resano and J. R. Castillo, Spectrochim. Acta, Part B, 2000, 55, 865-874.

3 H. F. Maltez, D. L. Borges, E. Carasek, B. Welz and A. J. Curtius, Talanta, 2008, 74, 800-805.

4 L. A. Portugal, H. S. Ferreira, W. N. L. dos Santos and S. L. C. Ferreira, Microchem. J., 2007, 87, 77-80.

5 M. G. A. Korn, G. L. dos Santos, S. M. Rosa, L. S. G. Teixeira and P. V. de Oliveira, Microchem. J., 2010, 96, 12-16.

6 J. Biasino, J. R. Dominguez and J. Alvarado, Talanta, 2007, 73, 962-964. 
7 E. R. Yourd, J. F. Tyson and R. D. Koons, Spectrochim. Acta, Part B, 2001, 56, 1731-1745.

8 D. K. Korkmaz, N. Ertaș and O. Y. Ataman, Spectrochim. Acta, Part B, 2002, 57, 571-580.

9 M. Shamsipur, F. Raoufi and H. Sharghi, Talanta, 2000, 52, 637-643.

10 W. H. Chan, R. H. Yang, T. Mo and K. M. Wang, Anal. Chim. Acta, 2002, 460, 123-132.

11 M. R. Ganjali, N. Motakef-Kazami, F. Faridbod, S. Khoee and P. Norouzi, J. Hazard. Mater., 2010, 173, 415-419.

12 E. Kirowa-Eisner, M. Brand and D. Tzur, Anal. Chim. Acta, 1999, 385, 325-335.

13 Y. Wu, N. B. Li and H. Q. Luo, Sens. Actuators, B, 2008, 133, 677-681.

14 S. Lee, S. Bong, J. Ha, M. Kwak, S.-K. Park and Y. Piao, Sens. Actuators, B, 2015, 215, 62-69.

15 K. Pokpas, N. Jahed, O. Tovide, P. G. Baker and E. I. Iwuoha, Int. J. Electrochem. Sci., 2014, 9, 5092-5115.

16 L. Fan, J. Chen, S. Zhu, M. Wang and G. Xu, Electrochem. Commun., 2009, 11, 1823-1825.

17 F. Zavarise, D. Merli and A. Profumo, Anal. Chim. Acta, 2010, 668, 177-181.

18 Z. Hu, C. J. Seliskar and W. R. Heineman, Anal. Chim. Acta, 1998, 369, 93-101.
19 S. Senthilkumar and R. Saraswathi, Sens. Actuators, B, 2009, 141, 65-75.

20 M. Ghiaci, B. Rezaei and R. J. Kalbasi, Talanta, 2007, 73, 3745.

21 S. Yuan, W. Chen and S. Hu, Talanta, 2004, 64, 922-928.

22 I. Cesarino, J. Braz. Chem. Soc., 2007, 18, 810-817.

23 G. Vlatakis, L. I. Andersson, R. Müller and K. Mosbach, Nature, 1993, 361, 645-647.

24 T. P. Rao, R. Kala and S. Daniel, Anal. Chim. Acta, 2006, 578, 105-116.

25 M. K. Bojdi, M. H. Mashhadizadeh, M. Behbahani, A. Farahani, S. S. H. Davarani and A. Bagheri, Electrochim. Acta, 2014, 136, 59-65.

26 M. F. Mousavi, A. Rahmani, S. M. Golabi, M. Shamsipur and H. Sharghi, Talanta, 2001, 55, 305-312.

27 L. Luo, X. Wang, Y. Ding, Q. Li, J. Jia and D. Deng, Appl. Clay Sci., 2010, 50, 154-157.

28 Y. Li, J. Liu, F. Yu, H. Tang, F. Zhao, B.-C. Ye, W. Chen and X. Lv, J. Electroanal. Chem., 2015, 758, 78-84.

29 W. Zhou, C. Li, C. Sun and X. Yang, Food Chem., 2016, 192, 351-357.

30 L. Wang, W. H. Xu, R. Yang, T. Zhou, D. Hou, X. Zheng, J. H. Liu and X. J. Huang, Anal. Chem., 2013, 85, 3984-3990. 